\title{
CONTRIBUTING FACTORS TO RELAPSE OF DRUG ADDICTION AMONG CLIENTS ATTENDING REHABILITATION CENTRES OF DHARAN, NEPAL S Sapkota ${ }^{1 *}$, A Khadka ${ }^{1}$, G Akela ${ }^{2}$
}

${ }^{1} \mathrm{JF}$ Institute of Health Sciences/Little Angels College of Higher /LACHS

2 Peoples Dental College and Hospital, Kathmandu, Nepal

*Correspondence to: Ms Sochana Sapkota, Lecturer, JF Institute of Health Sciences/Little Angels College of Higher /LACHS.

Email: sochana.sapkota@gmail.com

\begin{abstract}
Relapse is the resumption of substance after a period of abstinence. It is frustrating but frequent part of recovery process. Several substance including opiates, cocaine and alcohol have particularly has high relapse rate with majority of client relapsing within 1 year following treatment. The first 90 days after treatment are very vulnerable time. Hence, the objective of the study is to assess the contributing factors to relapse of drug addiction since the aftercare services, the psycho-social aspect of the treatment has been ignored and high relapse is prevalent among the treated clients. A descriptive cross-sectional study was carried out among clients attending three rehabilitation centres of Dharan using lottery method of simple random sampling among 72 respondents using structured questionnaires from 20th September to 4th October, 2015. Findings of the study showed that majority (63.9\%) of the respondents had started taking drugs again due to lack of self confidence. In addition to this another contributing factor to relapse was peer pressure (50\%) followed by inability to give old habits (44.4\%), easy accessibility of drugs (30.6\%). The finding also indicated that there was significant relationship (p value $=0.054$ ) between peer pressure and employment status. Lack of self-confidence, peer pressure, easy accessibility of drugs, lack of acceptance in society and family, adjustment problems had increased the chance of relapse after treatment. So, the treatment centres of Dharan should develop program that incorporate the overall development and treatment of client to prevent from relapse of drug addiction.
\end{abstract}

Key words: Addiction, Drug abuse, Relapse

\section{INTRODUCTION}

It has been reported globally even in countries with high rates of completion of inpatient treatment: $33 \%$ in Nepal , 55.8\% in China and $60 \%$ in Switzerland relapsed into drug use between 1 month and 1 year after discharge from treatment programmes. ${ }^{1}$ For instance in 2009, every 20 new cases of drug abuser reported daily in average, there were concurrently 24 cases of relapse detected in the same day. ${ }^{2}$ So this study aimed to assess contributing factors to relapse of drug addiction of among clients attending rehabilitation centers of Dharan.

Relapse is the resumption of substance after a period of abstinence. The first 90 days after treatment are very vulnerable time ${ }^{3} \ln 2007$, the detained fresh and 20 relapsed addicts were 6,679 and 7,810 respectively. Among the detained drug addicts in 2008, 5,939 (48\%) were fresh addicts while 6,413 (52\%) were relapsed addicts. Interestingly, in 2008 the statistics revealed a decline of percentages in total number detained addicts (15\%), new addicts (11\%) and relapsed addicts (18\%) compared to the reported statistics in $2007 .{ }^{5}$

It is not reasonable to expect that drug addicts will obtain lifelong abstinence with the first treatment experience. Even if addicts are treated successfully, often there will be occasional relapses. ${ }^{6}$ Research conducted on drug abuse, relapse and treatment in Kathmandu valley among 100 samples showed that 
relapse is due to higher expectation of parents that is $76 \%, 62 \%$ are not trusted on financial transaction, $62 \%$ face negative attitude and criticism, , 23\% easy availability of drugs and $20 \%$ due to lack of family. ${ }^{7,11}$ So the objective of this study was to assess the contributing factors to relapse of drug addiction.

\section{METHODS}

A Descriptive cross sectional design was used to assess contributing factors to relapse of drug addiction. Out of 90 relapsed drug abuser 72 were selected for study by using lottery method of simple random sampling. Respondent who hadn't passed primary level of education and those who were not willing to participate in study were excluded from study. The sample size for study was 72 .

The sample was calculated using formula $n=z^{2} p q /$ $\mathrm{e}^{2}$, where $\mathrm{z}$ : significance is $95 \%$ (1.96) and e: error is $10 \%(0.1), p=0.37$ and $q=0.62$; we get $n=72$. And the sample was calculated as: $n s=n /(1+n / N)$, where $\mathrm{N}=$ total no. of relapse drug abuser. So the sample required was found to be 72 . Obtained 72 samples were taken proportionally i.e. 24 samples from each rehabilitation centres using lottery method of simple random sampling. The samples include those clients who had relapsed at least once after the treatment. Structured questionnaire was developed by the researcher and questionnaire was used to collect the data from respondents during the study period of 3 weeks $\left(20^{\text {th }}\right.$ September to 4th October, 2015). The instrument consists of three sections: (i) Sociodemographical information of the respondents, (ii) Questions related to client's first drug use and related behaviour and (iii) Questions related to treatment of drug addiction and relapse.

Ethical clearance from Research Committee of JFIHS and college administration of Nursing Campus were taken for the study. Formal and informal permission was taken from the administrators of all the three rehabilitation centres of Dharan. Verbal consent was taken from respondents before taking interview, to participate in the study. Confidentiality of the respondents was maintained.

Analysis of data was done by SPSS version 20. All the data was arranged, coded, classified and tabulated to make it scientific and clear. The analysis was done by use of parameters like mean, percentage and standard deviation. The data obtained was analysed by using frequency distribution and percentage by using table. Chi square test was done to find out association between selected socio demographical variables and relapse of drug addiction.

\section{RESULTS}

TABLE 1: Socio-demographic Characteristics ( $n=72$ )

\begin{tabular}{|l|l|l|}
\hline Variables & $\begin{array}{l}\text { Frequency } \\
\text { (f) }\end{array}$ & $\begin{array}{l}\text { Percentage } \\
(\%)\end{array}$ \\
\hline
\end{tabular}

\begin{tabular}{|c|c|c|}
\hline Age group & \multicolumn{2}{|l|}{} \\
\hline $16-24$ & 25 & 34.7 \\
\hline $24-32$ & 28 & 38.8 \\
\hline $32-40$ & 13 & 18.0 \\
\hline $40-48$ & 6 & 8.3 \\
\hline Mean age \pm S.D. & $27.85 \pm 7.33$ & \\
\hline
\end{tabular}

Ethnicity

\begin{tabular}{|l|c|c|}
\hline Brahmin/Chhetri & 18 & 25.0 \\
\hline Newar & 17 & 23.6 \\
\hline Mongolian & 28 & 38.9 \\
\hline Dalit & 9 & 12.5 \\
\hline
\end{tabular}

Religion

\begin{tabular}{|l|c|c|}
\hline Hindu & 54 & 75.0 \\
\hline Buddhist & 5 & 6.9 \\
\hline Christian & 12 & 16.9 \\
\hline Kirat & 1 & 1.4 \\
\hline
\end{tabular}

\begin{tabular}{|c|c|c|}
\hline \multicolumn{2}{|l|}{ Educational level } \\
\hline Primary & 4 & 5.6 \\
\hline Secondary & 35 & 48.6 \\
\hline Higher secondary & 29 & 40.3 \\
\hline Higher studies & 4 & 5.6 \\
\hline
\end{tabular}

\begin{tabular}{|c|c|c|}
\hline \multicolumn{3}{|l|}{ Family type } \\
\hline Nuclear family & 42 & 58.3 \\
\hline Joint family & 27 & 37.5 \\
\hline Living alone & 3 & 4.2 \\
\hline \multicolumn{3}{|l|}{ Occupation } \\
\hline Unemployed & 39 & 54.2 \\
\hline Agriculture & 2 & 2.8 \\
\hline Business & 9 & 12.5 \\
\hline Service & 10 & 13.9 \\
\hline \multicolumn{3}{|l|}{ Other } \\
\hline Student & 12 & 16.7 \\
\hline
\end{tabular}

Table 1 shows that $38.8 \%$ of respondents were 
from 24 to 32 years. The finding also indicated that $38.9 \%$ of respondents were Mongolian. Majority (75\%) of respondents belong to Hindu religion. All the respondents were educated and $48.3 \%$ of respondents had completed secondary level of education. More than half $(58.3 \%)$ of respondents belong to the joint family. Only the small fraction of respondents (4.2\%) lives alone. About $55 \%$ of the respondents were unemployed. Only $2.8 \%$ were involved in agriculture. The findings also indicated that $12 \%$ respondents were student

TABLE 2: Age, Drug used and Reasons for Drug use for First Time $(n=72)$

\begin{tabular}{|c|c|c|}
\hline Variables & Frequency & Percentage \\
\hline \multicolumn{3}{|l|}{ Age of first drug use } \\
\hline Before 15 years & 20 & 27.8 \\
\hline $15-20$ years & 43 & 59.7 \\
\hline $20-25$ years & 9 & 12.5 \\
\hline \multicolumn{3}{|l|}{ First drug use* } \\
\hline Marijuana & 45 & 65.3 \\
\hline Heroine & 5 & 6.9 \\
\hline Tablet & 33 & 45.8 \\
\hline \multicolumn{3}{|l|}{ Others } \\
\hline Injection & 5 & 6.9 \\
\hline Phensydryl & 3 & 4.1 \\
\hline \multicolumn{3}{|c|}{ Reasons for drug use for first time* } \\
\hline Curiosity & 40 & 55.6 \\
\hline For entertainment & 41 & 56.9 \\
\hline Peer pressure & 33 & 45.8 \\
\hline Unemployment & 12 & 16.6 \\
\hline \multicolumn{3}{|l|}{ Others } \\
\hline Study failure & 6 & 8.3 \\
\hline For removing stress & 8 & 11.1 \\
\hline * Multiple Response & & \\
\hline
\end{tabular}

Table 2 shows that majority (59.7\%) of respondents had taken drugs between $15-20$ years of age. The finding also indicated that $65.3 \%$ of respondents had used Marijuana for the first time as it was commonly found. Entertainment (56.9\%) was the 22 major reasons for taking drugs for the first time followed by curiosity ( $55.6 \%)$, peer pressure $(45.8 \%)$, unemployment (16.6\%).

TABLE 3: Duration of Drug Abuse before Coming to Treatment, Frequency and Reason for Treatment $(n=72)$

\begin{tabular}{|c|c|c|}
\hline Variables & Freq. (f) & (\%) \\
\hline \multicolumn{3}{|c|}{ Duration of drug use before treatment } \\
\hline Less than 1 year & 35 & 48.6 \\
\hline 1-2 year & 19 & 26.4 \\
\hline 2-5 year & 13 & 18.1 \\
\hline 5-10 year & 4 & 5.6 \\
\hline More than 10 year & 1 & 1.4 \\
\hline
\end{tabular}

\section{Frequency of Treatment}

\begin{tabular}{|l|c|c|}
\hline Once & 2 & 2.7 \\
\hline Two times & 4 & 5.5 \\
\hline Three times & 29 & 40.2 \\
\hline Four times & 22 & 30.5 \\
\hline More than four times & 15 & 20.8 \\
\hline
\end{tabular}

Reasons for giving up drugs*

\begin{tabular}{|l|c|c|}
\hline Family pressure & 48 & 66.7 \\
\hline To do something in life & 36 & 51.4 \\
\hline Financial problem & 16 & 22.2 \\
\hline Fear of disease & 25 & 34.7 \\
\hline \multicolumn{2}{|l}{} \\
\hline Treatment Received * & 1 & 1.3 \\
\hline Treatment by medicine & 70 & 97.2 \\
\hline Spiritual therapies & 49 & 68.0 \\
\hline NA concept
\end{tabular}

* Multiple Responses

Table 3 states that about half of $(48.6 \%)$ of respondents had taken drugs for less than 1 year before coming to treatment for the first time. About $40 \%$ respondents had stayed three times in rehabilitation centers before this treatment. Majority of respondents (66.7\%) had given up drugs because of family pressure. Most of the respondents $(97.2 \%)$ were treated by spiritual therapies whereas $68 \%$ were treated by NA concept.

(C) 2016, JCMC. All Rights Reserved 
TABLE 4: Problems Related to Adjustment in Family, Society, Duration of Abstinence and Reasons for Relapse $(n=72)$

\begin{tabular}{|c|c|c|}
\hline Variables & Freq. (f) & $(\%)$ \\
\hline \multicolumn{3}{|l|}{ Problems in family* } \\
\hline Lack of trust & 37 & 51.4 \\
\hline $\begin{array}{l}\text { Family members thinking a } \\
\text { drug addict can never clear }\end{array}$ & 36 & 50.0 \\
\hline $\begin{array}{l}\text { Different Treatment from } \\
\text { family members }\end{array}$ & 40 & 55.6 \\
\hline High expectation & 23 & 31.9 \\
\hline \multicolumn{3}{|l|}{ Problems in society* } \\
\hline Lack of trust & 42 & 58.3 \\
\hline Hatred & 49 & 68.0 \\
\hline Lack of communication & 33 & 45.8 \\
\hline Problems with job & 27 & 37.5 \\
\hline \multicolumn{3}{|l|}{ Duration of abstinence } \\
\hline Within a month & 19 & 26.4 \\
\hline Between 1-2 months & 25 & 34.7 \\
\hline Between 3-6 months & 13 & 18.1 \\
\hline Between 6 months- 1 year & 8 & 11.1 \\
\hline Above 1 year & 7 & 9.7 \\
\hline \multicolumn{3}{|l|}{ Reasons for relapse } \\
\hline Inability to give old habits & 32 & 44.44 \\
\hline Easy accessibility of drugs & 22 & 30.6 \\
\hline Peer pressure & 36 & 50.0 \\
\hline Lack of self-confidence & 46 & 63.9 \\
\hline \multicolumn{3}{|l|}{ Others } \\
\hline Lack of love & 2 & 2.7 \\
\hline Unemployment & 5 & 6.9 \\
\hline Being alone & 1 & 1.3 \\
\hline Family problems & 7 & 9.7 \\
\hline Frustration & 7 & 9.7 \\
\hline
\end{tabular}

*Multiple Responses

Table 4 reveals that majority (51.4\%) of respondents faced lack of trust followed by family members thinking, a drug addict can never be clear (50\%) after their treatment in family.Majority of respondents (34.7\%) relapsed between 1 -2 months after treatment.Majority (63.9\%) of respondents relapsed due to lack of self confidence. About $50 \%$ of respondents relapsed due to peer pressure .minority of respondents relapsed due to other reasons like frustration, lack of love, unemployment, family problems and being alone.

TABLE 5: Association between Peer Pressure (Factor of Relapse) and Educational Level, Employment Status, Treatment Modality

\begin{tabular}{|c|c|c|c|c|}
\hline \multirow{2}{*}{ Variables } & \multicolumn{2}{|c|}{ Peer Pressure } & \multirow{2}{*}{$\begin{array}{c}\text { Pearson } \\
\text { Chi- } \\
\text { Square }\end{array}$} & \multirow{2}{*}{$\begin{array}{c}\mathrm{P} \\
\text { value }\end{array}$} \\
\hline & No & Yes & & \\
\hline \multicolumn{5}{|c|}{ Educational level } \\
\hline Primary & $1(25.0 \%)$ & $3(75.0 \%)$ & \multirow{4}{*}{2.063} & \multirow{4}{*}{0.559} \\
\hline Secondary & $17(48.5 \%)$ & $18(51.5 \%)$ & & \\
\hline $\begin{array}{l}\text { Higher } \\
\text { secondary }\end{array}$ & $15(51.7 \%)$ & $14(48.3 \%)$ & & \\
\hline $\begin{array}{l}\text { Higher } \\
\text { studies }\end{array}$ & $3(75.0 \%)$ & $1(25.0 \%)$ & & \\
\hline \multicolumn{5}{|c|}{ Employment status } \\
\hline Unemployed & $14(35.8 \%)$ & $25(64.2 \%)$ & \multirow{5}{*}{7.644} & \multirow{5}{*}{0.054} \\
\hline Agriculture & $2(100.0 \%)$ & $0(0.0 \%)$ & & \\
\hline Services & $6(66.6 \%)$ & $3(33.3 \%)$ & & \\
\hline Business & $7(70.0 \%)$ & $3(30.0 \%)$ & & \\
\hline Student & $7(58.3 \%)$ & $5(41.7 \%)$ & & \\
\hline \multicolumn{5}{|c|}{ Treatment modality* } \\
\hline $\begin{array}{l}\text { Treatment } \\
\text { by medicine }\end{array}$ & 1(100.0\%) & $0(0.0 \%)$ & 1.794 & 0.314 \\
\hline $\begin{array}{l}\text { Spiritual } \\
\text { therapy }\end{array}$ & $36(51.4 \%)$ & $34(48.6 \%)$ & 2.057 & 0.493 \\
\hline NA concept & $19(38.7 \%)$ & $30(61.3 \%)$ & 3.730 & 0.465 \\
\hline
\end{tabular}

* Multiple Response

Table 5 states that there is no significant relationship between peer pressure (factor of relapse) and educational level at 95\% confidence level using chi square test whereas findings shows the significant relationship between peer pressure and employment status ( $p$ value $=0.054$ ). The table also states that unemployment decrease chance of finding holding addiction which increases the risk of relapse drug dependence. 


\section{DISCUSSION}

Studies such as the National Survey on Drug Use and Health, stated that some children are already abusing drugs by age 12 or 13, which likely means that some may begin even earlier. In contrast in this study shows that majority (59.7\%) started using drug at $15-20$ years of age.

In this study majority (65.3\%) of respondents used marijuana for their first time which is supported by study which stated that $65.7 \%$ used marijuana as it is easily available. ${ }^{8}$ This finding is supported by the study of Central Bureau Statistics. ${ }^{9}$ Current study reveals that reasons for their first drug abuse were for entertainment (56.9\%), curiosity (53.9\%), peer pressure $(45.8 \%)$, which are consistent with the causes given by drug abuse by in which major reasons were entertainment (54\%) followed by curiosity $(50 \%){ }^{10}$

This study states that majority $(40.2 \%)$ had went to treatment process for three times mainly due to the family pressure $(66.7 \%)$, to do something in life $(51.4 \%)$ which is supported by the study which states that majority of respondents went to treatment process for 1 to 5 times and family pressure was the main reason to gave up the drugs. With regard to the treatment modality majority are treated with spiritual therapies (97.2\%) and NA concept (68.1\%) which is contrast to the findings of study which states that $24 \%$ respondents were treated with medicine, $22 \%$ with spiritual healing. ${ }^{7} T$ The variation may be due to the different treatment modalities used by different treatment centers according to their philosophy and beliefs.

Study had stated that perceived family support, family relationship, family behaviours, involvement in family plays the vital role in preventing relapse in which only $22 \%$ respondents feel accepted in family. ${ }^{8}$ This finding is supported in this study because majority of the respondents had only tolerable relation with family members; majority (52.8\%) didn't feel accepted in family members.

The respondents faced different adjustment problem after being discharged from the treatment centers. This study reveals that faced different treatment by family members $(55.6 \%)$, lack of trust (51.4\%), family members thinking, a drug addict can never be clear (50\%) as the major problems faced by respondents. In contrast to this, study had stated that major problems faced by respondents $62 \%$ was the high expectation from their family members after being discharged from rehabilitation centers. ${ }^{1}$ This variation may be due to situational and cultural difference in which respondents reside.

With regard to the feeling of acceptance in society, the research findings shows that majority (62.5\%) of respondents didn't felt accepted in society and faced different adjustment problems in society like hatred (68\%), lack of trust (58.3\%), lack of communication (58.3\%), problems with job (37.5\%). This finding is supported by the study which states that $92 \%$ faced communication gap, $86 \%$ lack of trust, $54 \%$ difficulty in job, 32\% feel avoidance and negative attitude as the major problems in adjustment in society. ${ }^{7}$

The first 90 days is the most vulnerable period to the relapse of drug addiction which supports the findings of the current study as the $26.4 \%$ respondents within a month, $34.7 \%$ respondents within a 1-2 month start using drugs after discharge from treatment centers. ${ }^{11}$

A study had showed that $30 \%$ had enjoyment with this drug use for which they started it again, 34\% peer pressure, $8 \%$ to relieve stress, $8 \%$ to socialize, as factors associated with relapse. ${ }^{12}$ In contrast to this, present study reveals that causes of relapse were lack of self confidence (63.9\%), peer pressure (50\%), inability to give old habit (44.3\%), easy access of the drugs (30.6\%). The variation may be due to personality difference of different respondents. Hence, the present study reveals that major cause of relapse after undergoing the treatment process are lack of self confidence, peer pressure, inability to give old habit, easy access of drugs, lack of family and social acceptance and family and social adjustment problems.

\section{CONCLUSION}

This descriptive study was conducted to identify the contributing factors to the relapse of drug addiction of the clients attending the rehabilitation centres of Dharan. The data were collected from 72 respondents using the lottery method of probability sampling from the relapse drug abuser of three rehabilitation centres of Dharan. 
From the findings, it can be concluded that relapse occurs in the first 90 days after treatment in this study. Lack of self confidence was one of the most important factors contributing to the relapse of drug addiction. In addition to peer pressure, is another major contributing factor followed by inability to give up old habits and easy accessibility of drugs. Further the finding also indicated that lack of family and social acceptance after treatment and family/social adjustment problems were the problems that drug user had to face after discharge from rehabilitation centers. The finding also indicated that there was significant relationship between peer pressure and employment status.

\section{ACKNOWLEDGEMENTS}

Researcher would like to express special thanks and sincerity to JF Institute of Health Sciences for providing this golden opportunity to conduct the research study. Researchers express a great sense of gratitude towards Prof. Radha Ranabhat. Researchers would also like to extend heartiest appreciation to study participants for providing necessary information for this study and administrator of rehabilitation centres for providing permission to conduct study.

\section{REFERENCES}

1. Maehira Y, Maarlatt G, Gordan J. Determination of replase: implication for maintenance of behavioural change. Davidson Newyork: Brunner Mazel; 2013:24(1).

2. Ibrahim F, Kumar N. Factor's affecting drug replase in Malaysia empirical evidence. Journal on Asian Social Science. 2009:5(12).
3. Hunt W, Barnet L, Branch L. Relapse rates in addiction programme. Journal of clinical psychology.1971;2(4):456

4. National Institute of Drug Abuse.Drugs facts: heroine. Journal of addiction USA. 2008:4(12).

5. Niraula S, Chhetry DB,Singh G, Negash S, Shyangwa PM. Role of rehabilitation centres in reducing drug abuse problem in a town of Eastern Nepal.Kathmandu University Medical Journal. 2006; 4(16):448-454.

6. LesnerA. Recovery and Craving .Journal of Moyers of addiction Newyork.2008:6(5).

7. Pun C, Niraula P. Research study on drug abuse relapse and treatment in Kathmandu valley, Journal of Health Research Council. NHRC.2001; 4(1).

8. Budhathoki K, Shrestha S, Acharya M, Manadhar G. Substance use among third year medical students. Nepal Health Research Council Journal. 2006:8(1).

9. Central Bureau of Statistics. Survey report on current hard drug users Nepal, Nepal health Ministry, Kathmandu, Nepal.2069.

10. Sharma A, Upadhyaya S, Pankaj B, Nijhawan N. A study of 2:2(1); 31-35.

11. Henkel D. Unemployment and substance use. Journal on current drug abuse.2011:4(27).

12. Sunder S, Kaur S, Kaur J. A study of drug relapse and its associated factors among cases admitted in Swami Vivekananda Drug Deaddiction Centre, GMC, Amritsar. International Journal of Interdisciplinary and Multidisciplinary Studies (IJIMS).2014:, 2 (2);100-105. 